\title{
Mulheres, paz e segurança na América do Sul: o processo de implementação de uma agenda chave
}

\author{
Women, peace and security in South America: the process of implementing a key agenda
}

DOI: https://doi.org/10.22456/2178-8839.103179

Natália Diniz Schwether Escola de Comando e Estado Maior do Exército, Rio de Janeiro, Brasil natidiniz@gmail.com

\section{Resumo}

A Resolução 1325 da Organização das Nações Unidas é a normativa internacional mais importante sobre o impacto do conflito na vida de mulheres e meninas. Aborda a proteção contra a violência sexual e baseada no gênero, promove a participação feminina nos processos de paz e amplia o papel das mulheres em missões. O processo de implementação nos Estados-membros é realizado através da formulação de Planos de Ação Nacionais (PANs), os quais são responsáveis pelo estabelecimento de ações estratégicas, identificação de prioridades, alocação de recursos, determinação de responsabilidades e prazos de execução. Na região sul-americana foram produzidos, após vinte anos da primeira solicitação, apenas cinco planos, pela Argentina, Chile, Brasil e Paraguai. Diante disso, o artigo centra-se em dois principais questionamentos: como se deu a produção dos PANs em cada um desses países? E, quais são as principais diferenças entre eles? Portanto, em uma primeira etapa, este estudo apresenta a evolução da agenda Mulheres, Paz e Segurança e seus desdobramentos. Em um segundo momento, um protocolo de análise textual é aplicado com o intuito de comparar os planos dos países sulamericanos. Por fim, constata-se que as áreas de atribuição de recursos e formulação de estratégias de monitoramento e avaliação exigem maior diligência.

Palavras-chave: Resolução 1325; Planos de Ação Nacionais; América do Sul.

\section{Abstract}

United Nations Resolution 1325 is the most important international standard regarding the conflict's impact on the lives of women and girls. It addresses protection against sexual and gender-based violence, promotes female participation in peace processes and expands the role of women in missions. The implementation process in the Member States is carried out through the formulation of National Action Plans (NAPs), which are responsible for establishing strategic actions, identifying priorities, allocating resources, determining responsibilities and execution deadlines. In the South American region, only five plans were produced, twenty years after the first application, by Argentina, Chile, Brazil and Paraguay. Given this, the article focuses on two main questions: how did the production of NAPs in each of these countries take place? And, what are the main differences between them? Therefore, in a first stage, this study presents the evolution of the Women, Peace and Security agenda and its consequences. In a second step, a textual analysis protocol is applied in order to compare the plans implemented by each of the South America countries. Finally, it appears that the areas of resource allocation and monitoring and evaluation strategies require greater diligence.
\end{abstract}

Keywords: 1325 Resolution; National Action Plans; South America. 


\section{Introdução}

As mulheres estão ativas na arena internacional há muitos anos. O primeiro movimento organizado dedicado à igualdade política para as mulheres iniciou em 1848 (ano da celebração da Convenção de Seneca Falls): as sufragistas buscavam ampliar os direitos políticos através do voto feminino. Lutavam, também, por educação e emprego (GRADY, 2018).

Na década de 1960, o movimento feminista encontrou novamente um objetivo capaz de unificá-lo: a igualdade social. O lema “o pessoal é político” expôs temas, até então, reservados ao âmbito privado - sexo, relacionamentos, aborto, trabalho doméstico - à discussão na arena pública, haja vista a expressão dessas questões para o alcance da igualdade. A luta resultou na possibilidade de as mulheres terem acesso ao controle da natalidade e o direito à educação. Atuou, igualmente, na prevenção da violência doméstica e contra o abuso sexual no ambiente de trabalho (GRADY, 2018).

Anos mais tarde, na década de 1990, o pleito feminino reivindicou, em especial, pelo aumento do número de mulheres em espaços de poder. Para além disso, evidenciou a característica interseccional das demandas, uma vez que revelou como as diferentes formas de opressão interagem - raça, classe, nacionalidade, sexualidade (FRASER, 2013; GRADY, 2018).

A conjuntura atual é marcada pelo uso intenso da tecnologia, as redes (Facebook, Twitter, YouTube) são o ambiente comum para o encontro e o planejamento das ações, lugar em que o debate feminista se realiza e se aprofunda, por vezes, transbordado para as ruas. O feminismo contemporâneo é caracterizado por sua diversidade de propósitos e cacofonia de vozes, dentre as questões estão: a inclusão-trans, a rejeição da heterocisnormatividade ${ }^{1}$ e a descoberta de aspectos positivos no corpo (body-positive) (MUNRO, 2013).

No que diz respeito a promoção dos direitos das mulheres foi a Convenção para Eliminação de todas as Formas de Discriminação Contra as Mulheres (CEDAW), aprovada em 1979, pela Assembleia Geral das Nações Unidas, o instrumento que pela primeira vez tratou, em profundidade, os problemas enfrentados pelas mulheres. Até aquele momento, os principais documentos internacionais, a exemplo da Carta Internacional dos Direitos Humanos (1948), se limitavam a afirmar a igualdade entre os seres humanos e o princípio da não-discriminação por sexo; os atos de violência e as leis discriminatórias em relação à população feminina não tinham espaço para consideração.

A CEDAW abordou questões como a equidade feminina, os direitos na família e o acesso à educação e à saúde. Ela foi essencial para mobilizar atenção a temas pouco evidenciados, sendo o tratado de Direitos Humanos mais ratificado. $\mathrm{O}$ seu sucesso ficou comprometido, contudo, ao não ser completamente implementada pelos Estados signatários, muito em virtude da falta de mecanismos para tanto (AFSHARIPOUR, 1999; TITUNIK, 2000).

As articulações transnacionais de mulheres conquistaram espaço, também, por meio de uma série de conferências realizadas no âmbito da Organização das Nações Unidas (ONU). A representação feminina, mediada por organizações não governamentais (ONGs) incorporou demandas específicas das mulheres nos tópicos em debate. O feito foi visto como um grande sucesso do movimento de direitos das mulheres, não sem críticas ao passo que teria sido condescendente com a agenda masculinizada² da instituição (WEST, 1999; FRIEDMAN, 2003).

A Primeira Conferência Mundial sobre a Mulher foi realizada na Cidade do México, em 1975, e estabeleceu a Década da Mulher (1976-1985), período no qual o tema da persistente discriminação contra as mulheres recebeu atenção especial. A Segunda e a Terceira Conferência Mundial sobre a Mulher foram realizadas respectivamente na cidade de Copenhague, em 1980, e Nairóbi, em 1985. Entre os principais tópicos da agenda estavam educação, oportunidades de trabalho e acesso à saúde.

\footnotetext{
${ }^{1}$ Trata-se da rejeição de padrões pré-estabelecidos de gênero de acordo com o sexo biológico.

${ }^{2}$ Os primeiros esforços de atuação das mulheres na ONU motivaram, ao mesmo tempo, processos contrários, uma vez que diversas mulheres se sentiam excluídas das políticas elitistas da Organização, as quais viam que, de forma recorrente, suas demandas eram ignoradas e não reconhecidas em uma Organização dominada por homens, que assim como outras constrói, de forma autorizada, suas normas de forma a privilegiar os traços associados à masculinidade (WEST, 1999; FRASER, 2006).
} 
Na Conferência Mundial sobre Direitos Humanos, em Viena, no ano de 1993, as mulheres pleitearam por dois principais objetivos: gendrificar os Direitos Humanos e responsabilizar o Estado por ações de violência contra as mulheres, não apenas na esfera pública, mas, principalmente, no âmbito privado. Como resultado, o documento final da convenção dedicou toda uma seção para o tema dos Direitos Humanos das mulheres e incluiu recomendações para sua proteção (FRIEDMAN, 2003).

A violência perpetrada contra as mulheres foi tema de discussão, também, na Assembleia Geral da Organização dos Estados Americanos (OEA) reunida em Belém do Pará, no ano de 1994. Naquela oportunidade foi aprovada a Convenção Interamericana para Prevenir, Punir e Erradicar a Violência Contra a Mulher, ou a Convenção de Belém do Pará. Essa Convenção considera a violência contra a mulher uma violação dos Direitos Humanos e das liberdades fundamentais, em geral, ignorada por uma sociedade marcada por relações de poder desiguais (BARSTED, 2006).

A Convenção despertou a atenção da Sul-América para o tema, a Argentina foi o primeiro país a inseri-la em seu quadro de leis quando, em dezembro de 1994, sancionou a Lei 24.417 e inovou ao prever a exclusão do agressor do domínio familiar. O Paraguai aderiu à Convenção em 1995 e adotou, em 2000, a Lei 1.600 no combate à violência doméstica. O Brasil ratificou a Convenção em 1995 e, embora abordasse a problemática desde a década de 1980³ , apenas em 2006 promulgou a Lei 11.340 (Lei Maria da Penha). O Chile ratificou a Convenção em 1996, porém as iniciativas pela igualdade de gênero remontam a década de 1970, a exemplo do Serviço de Proteção à Mulher (MATHIAS, 2009).

A Quarta Conferência Mundial sobre a Mulher, realizada em Pequim, no ano de 1995, ficou conhecida como "a maior e a mais importante delas" (VIOTTI, 2006, p. 148). Um de seus principais feitos foi o estabelecimento da Declaração e Plataforma de Ação, com objetivos e ações necessárias para doze áreas prioritárias. Ela inovou ao empregar o conceito de gênero; reavaliando as estruturas sociais e as relações entre homens e mulheres culturalmente determinadas (VIOTTI, 2006).

A inserção do componente feminino e da igualdade de gênero na agenda desafiou os paradigmas mundiais e abriu uma oportunidade para reflexão, indo além de uma simples melhoria do padrão já existente, para propor uma reconceitualização política, na qual a participação e a consulta aos grupos de mulheres, experientes e detentoras de conhecimento, integrasse a ação (GYA, 2007).

Tendo em vista a busca por transversalidade do tema e novas abordagens, os debates recaíram também, sob o campo da segurança e defesa internacional, um encontro pouco usual; pois, seja na academia ou na sociedade civil, especialistas em segurança, em geral, não se atêm a temática de gênero, assim como estudiosos de gênero não se debruçam sob a segurança (DONADIO; RIAL, 2015).

No ano 2000, o Conselho de Segurança das Nações Unidas (CSNU) iniciou a proposição de uma série de resoluções com a temática: Mulheres, Paz e Segurança (MPS). Até aquele momento, apenas a Declaração sobre a Participação das Mulheres na Promoção da Paz Internacional e da Cooperação aprovada em reunião plenária da Assembleia Geral da ONU, no ano de 1982, durante a Década da Mulher, fazia menção às mulheres ${ }^{4}$.

A atenção especial para a questão das mulheres não ocorreu sem ressalvas, o descontentamento por parte de alguns Estados baseava-se em uma suposta duplicação de esforços e sobreposição de mandatos, haja vista a existência de outros órgãos e agências tradicionais do sistema ONU competentes para lidarem com a temática. Em contrapartida, o debate expandido do tema foi defendido por países, como a Austrália, que destacaram a relevância e a pertinência do assunto, bem como a conquista de uma maior transparência na condução das ações (REBELO, 2017).

Desse modo, é sob a agenda MPS que esse artigo se debruça, com dois principais objetivos: apresentar o seu desenvolvimento ao longo dos últimos vinte anos (desde a resolução original até o documento mais recente veiculado) e

${ }^{3}$ A Constituição de 1988 foi um importante instrumento de promoção política das mulheres.

${ }^{4}$ A Declaração afirmava a contribuição das mulheres aos processos de promoção da paz e cooperação, resguardando seu direito de participação, em uma distribuição equitativa de papéis entre mulheres e homens. Mencionava, ainda, a necessidade de empreender esforços para encorajar e intensificar a participação feminina nesses processos, assim como de tomar medidas apropriadas para com as mulheres vítimas de violações de Direitos Humanos (Res. 37/63, 1982). 
analisar os Planos de Ação Nacionais (PANs) de Argentina, Brasil, Chile e Paraguai, como instrumento de implementação dessa agenda. Os esforços empíricos concentram-se, sobretudo, no segundo ponto, buscando responder: como se deu a produção dos PANs em cada um desses países? Quais são suas principais diferenças?

O estudo está circunscrito aos quatro países sul-americanos que até a presente data produziram e apresentaram um plano à sociedade. Em comum esses países detêm um passado autoritário e intrincadas transições democráticas, seja pela completa debandada dos militares do poder, como na Argentina, ou pelo controle sobre o processo, como no Brasil. Enfrentam, ainda, a ausência de hipóteses de guerra, o que compromete a compreensão social do papel das Forças Armadas, bem como o seu preparo.

Paralelamente, há, nas últimas décadas, o crescimento da participação feminina no mercado de trabalho, as quais mais conscientes de seus direitos competem por profissões consideradas por muito tempo masculinas, dentre elas as carreiras militares; nestes países, os primeiros ingressos em postos oficiais datam da década de 1980, já os postos de comando foram atingidos no final da década de 1990. Na política, a Argentina se sobressai em relação aos demais países, a julgar pela forte participação feminina no Parlamento nacional (SAINT-PIERRE, 1995; MATHIAS, 2009; CEPAL; OIT, 2019).

O enfoque nos PANs é conferido em razão de sua fundamental importância para a implementação das ações exigidas pela agenda. É por meio deles que os Estados signatários definem estratégias, identificam prioridades, alocam recursos, determinam responsabilidades e prazos de execução. Por fim, depreende-se que o PAN, tal como qualquer outra política estatal requer atenção e dedicação constante a fim de que mudanças substantivas possam ser alcançadas, especialmente no que tange a destinação de recursos e o estabelecimento de estratégias para monitoramento e avaliação.

\section{Contexto}

A apresentação realizada ao início permite adentrar esse primeiro tópico consciente de que a adoção da agenda MPS está inserida e faz parte de um contexto histórico particular. Nesse sentido, recorda-se, especialmente, que, em 1995, a Conferência de Pequim situou a questão das mulheres e conflitos armados como uma área prioritária de atenção. Cinco anos após, em Nova Iorque, em uma sessão especial de balanço das ações, admitiu-se que uma maior ênfase deveria ser concedida à temática (TRYGGESTAD, 2009).

A importância da agenda ampliou-se ao ser constatado que os conflitos armados são responsáveis por agravar as disparidades entre mulheres e homens. As mulheres e as crianças são o grupo mais afetado pela guerra: vítimas de violência sexual, excluídas dos processos de reconstrução e sem acesso às novas oportunidades pós-conflito (POPOVIC; LYYTIKAINEN; BARR, 2010). Não obstante, adentrar a agenda do CSNU exigiu grande esforço, tanto de mulheres membros de ONGs quanto daquelas inseridas no sistema $\mathrm{ONU}^{5}$, afinal discutir questões alheias às preocupações centrais dos Estados membros, em geral, não despertava grande interesse (TRYGGESTAD, 2009).

Dessa forma, após intensos estudos ${ }^{6}$ a Resolução 1325 foi desenvolvida, sem se ater a um contexto ou conflito específico, podendo ser aplicada em países que vivenciam um conflito e carecem de medidas imediatas e em países considerados estáveis, que necessitam aprimorar as questões de gênero (UNDP, 2019).

A Resolução 1325 foi a primeira iniciativa projetada para encorajar os Estados Membros a aumentarem a representação feminina nos processos decisórios e em missões e incorporarem uma perspectiva de gênero nas operações de manutenção da paz, por meio de treinamentos e elaboração de acordos; solicitou, ainda, medidas especiais para

\footnotetext{
${ }^{5}$ Naquela circunstância quatro instâncias das Nações Unidas se concentravam na igualdade de gênero e no empoderamento das mulheres: Divisão para o Avanço das Mulheres (DAW, criada em 1946), Instituto Internacional de Pesquisas e Capacitação para a Promoção da Mulher (INSTRAW, criada em 1976) Escritório de Assessoria Especial em Questões de Gênero (OSAGI, criada em 1997) e Fundo de Desenvolvimento das Nações Unidas para a Mulher (UNIFEM, criada em 1976). Em 2010, a Assembleia Geral da ONU votou por unanimidade a criação de uma nova entidade, denominada ONU Mulheres. ${ }^{6}$ Destacam-se os estudos elaborados para apresentação em fórum realizado na Namíbia, no ano 2000. Os debates nessa circunstância deram origem ao Plano de Ação da Namíbia “Mainstreaming a Gender Perspective in Multidimensional Peace Support Operations”.
} 
proteção contra a violência, com atenção, ao estupro e outras formas de abuso sexual, responsabilizando os culpados; e a produção e a apresentação de relatórios (CSNU, 2000).

A despeito da importante mensagem que a aprovação dessa Resolução detinha, ela enfrentou grandes desafios, sobretudo, no seu processo de implementação. Por um lado, a falta de mecanismos que possibilitassem a sua supervisão e, por outro o seu direcionamento estritamente técnico, ocasionaram dificuldades práticas para a integração efetiva de mulheres nas mesas de negociação e, principalmente, na realização de transformações políticas (TRYGGESTAD, 2009). Em decorrência disso, outras resoluções foram demandas, cada qual com ênfase em uma temática.

Enquanto a Resolução 1325 não ultrapassava três páginas, aquelas que a suplementaram são bem mais extensas, no ímpeto de adicionar detalhes que se constataram ausentes. No entanto, nenhuma delas possui caráter vinculante; ou seja, não estão previstas sanções formais ou penalidades para os Estados membros que a descumprirem, são proposições que encorajam os governantes no avanço de importantes pautas (MILLER; POURNIK; SWAINE, 2014).

Dessa forma, em 2008, foi aprovada a Resolução 1820 a qual se ateve à violência sexual como tática de guerra. A resolução adotou linguagem mais incisiva, destacou, por exemplo, a enorme brutalidade dos atos e a consternação pela persistência e sistematização das ocorrências. Por meio de dezesseis princípios exigiu o fim por completo de todos os casos, a adoção de medidas para proteção dos civis e a execução de programas de capacitação, juntamente com uma política de tolerância zero. Destacou, ainda, a necessidade de processar os indivíduos responsáveis pelos atos e de se aplicar sanções aos Estados (CSNU, 2008).

A Resolução 1888, de 2009, mais extensa que as anteriores, estabeleceu vinte e nove pontos de forma a aprofundar o tema da violência sexual (CSNU, 2009a). No mesmo ano a Resolução 1889 foi adotada e retomou a questão da participação de mulheres nos processos de paz, solicitou, nesse sentido, que estratégias fossem formuladas para formação apropriada e apresentação de relatórios com informações detalhadas (CSNU, 2009b).

No curso de iniciativas do CSNU para a agenda MPS, foi adotada, em 2010, a Resolução 1960, que exigiu a formatação de compromissos e cronogramas precisos. Em 2013, outras duas resoluções foram firmadas, a Resolução 2106 visando combater a impunidade e a Resolução 2122 que propôs maior interação com a sociedade civil e transversalização da agenda para áreas afins. A Resolução 2242 foi estabelecida, em 2015, e deu ênfase a importância do empoderamento feminino no enfrentamento da violência (MRE, s.a).

O último documento aprovado para compor a agenda foi a Resolução 2467, de 2019, seu preâmbulo revelou a preocupação com o lento avanço de iniciativas para eliminar a violência sexual em situações de conflito armado. Em trinta e sete pontos reiterou a exigência do fim imediato de todos os atos de violência sexual, a necessidade de elaboração de códigos de conduta que proíbam a violência, de planos concretos e de prazos a serem cumpridos, bem como reforços na legislação e a apresentação periódica de informes (CSNU, 2019).

Em síntese, aquilo que é central a essas resoluções pode ser condensado em quatro pilares principais: participação, proteção, prevenção e recuperação; e, um quinto pilar normativo ${ }^{7}$ (KIRBY; SHEPHERD, 2016). Logo, teríamos a participação das mulheres nos processos de paz, seguido pela inserção de uma perspectiva de gênero em todas as atividades de prevenção de conflitos, acompanhado pela proteção das mulheres em períodos de guerra e paz e, finalmente, a recuperação das capacidades de ação e fortalecimento das mulheres no pós-conflito (UNDP, 2019).

As resoluções 1820, 1888 e 1889 ressaltam, ademais, a importância da acusação dos perpetradores de violência sexual baseada em gênero (POPOVIC; LYYTIKAINEN; BARR, 2010). O Quadro 1 reúne as resoluções que conformam a agenda MPS e suas temáticas centrais:

\footnotetext{
${ }^{7}$ Em 2010 o Secretário Geral considerou que o pilar normativo estaria presente nos demais, diante disso foram delineados indicadores para as outras quatro áreas temáticas. Entretanto, em alguns casos o pilar normativo permanece aparecendo de forma isolada (KIRBY; SHEPHERD, 2016).
} 
Quadro 1-Assuntos centrais nas Resoluções MPS/CSNU

\begin{tabular}{|c|c|c|}
\hline Resolução & Ano & Assuntos Centrais \\
\hline $\begin{array}{l}\text { Resolução } 1325 \text { do Conselho de Segurança das } \\
\text { Nações Unidas }\end{array}$ & 2000 & $\begin{array}{l}\text { Marco jurídico, político e histórico que reconhece a } \\
\text { importância da participação das mulheres e a inclusão da } \\
\text { perspectiva de gênero nas negociações de paz. }\end{array}$ \\
\hline $\begin{array}{l}\text { Resolução } 1820 \text { do Conselho de Segurança das } \\
\text { Nações Unidas }\end{array}$ & 2008 & $\begin{array}{l}\text { A Resolução identifica a violência sexual como uma ameaça a } \\
\text { paz e a segurança internacional, a qual necessita de uma } \\
\text { resposta. Reconhece a violência sexual como prática de guerra. }\end{array}$ \\
\hline $\begin{array}{l}\text { Resolução } 1888 \text { do Conselho de Segurança das } \\
\text { Nações Unidas }\end{array}$ & 2009 & $\begin{array}{c}\text { Fornece conhecimentos especializados e a melhora da } \\
\text { coordenação para resposta da violência sexual associada a } \\
\text { situações de conflito. }\end{array}$ \\
\hline $\begin{array}{l}\text { Resolução } 1889 \text { do Conselho de Segurança das } \\
\text { Nações Unidas }\end{array}$ & 2009 & $\begin{array}{l}\text { Estabelece indicadores mundiais, reitera a necessidade de } \\
\text { aumentar a participação de mulheres e de incorporar a } \\
\text { perspectiva de gênero em todos os processos de decisão, } \\
\text { especialmente nas fases iniciais de consolidação da paz. }\end{array}$ \\
\hline $\begin{array}{l}\text { Resolução } 1960 \text { do Conselho de Segurança das } \\
\text { Nações Unidas }\end{array}$ & 2010 & $\begin{array}{l}\text { Sistema de responsabilidade fiscal para acabar com a violência } \\
\text { sexual associada a situações de conflito. Elaboração de listas de } \\
\text { agressores e informes anuais sobre suspeitos. }\end{array}$ \\
\hline $\begin{array}{l}\text { Resolução } 2106 \text { do Conselho de Segurança das } \\
\text { Nações Unidas }\end{array}$ & 2013 & $\begin{array}{c}\text { Estados Membros e entidades da ONU devem fazer mais para } \\
\text { implementar os mandatos anteriores e combater a } \\
\text { impunidade. }\end{array}$ \\
\hline $\begin{array}{l}\text { Resolução } 2122 \text { do Conselho de Segurança das } \\
\text { Nações Unidas }\end{array}$ & 2013 & $\begin{array}{l}\text { Estados Membros e entidades da ONU devem estabelecer um } \\
\text { calendário de trabalho. Será feita uma avaliação do progresso } \\
\text { na aplicação da Resolução } 1325 .\end{array}$ \\
\hline $\begin{array}{l}\text { Resolução } 2242 \text { do Conselho de Segurança das } \\
\text { Nações Unidas }\end{array}$ & 2015 & $\begin{array}{c}\text { Clama aos Estados Membros que avaliem suas estratégias e } \\
\text { recursos para a implementação da agenda sobre mulheres, paz } \\
\text { e segurança e reitera o chamado aos Estados para que velem } \\
\text { por uma maior representação das mulheres em todos os níveis } \\
\text { de decisão das instituições nacionais, regionais e } \\
\text { internacionais. }\end{array}$ \\
\hline $\begin{array}{c}\text { Resolução } 2467 \text { do Conselho de Segurança das } \\
\text { Nações Unidas }\end{array}$ & 2019 & $\begin{array}{c}\text { Encoraja os Estados Membros que sigam intensificando } \\
\text { esforços para documentar, combater e punir a violência sexual } \\
\text { em situações de conflito armado. }\end{array}$ \\
\hline
\end{tabular}

Fonte: Elaborado pela autora com dados de CSNU (2000, 2008, 2009a, 2009b, 2010, 2013a, 2013b, 2015, 2019).

A apreensão do conjunto das resoluções demonstra a grande ambição dos objetivos da agenda MPS, na tentativa de reconfigurar as dinâmicas de poder inerentes ao gênero ${ }^{8}$. Uma análise mais detida demonstra que foi conferida maior atenção à prevenção da violência e proteção das mulheres, em comparação à sua participação na construção da paz; apenas a Resolução 1889 e a Resolução 2122 abordaram prioritariamente a participação (KIRBY; SHEPHERD, 2016).

Por conseguinte, as resoluções de forma recorrente apresentaram a mulher como um sujeito de proteção, carente de intervenção de terceiros para salvaguardar sua própria segurança no meio internacional (SOTO; PARDO, 2016). A vitimização feminina foi a maneira formal encontrada pelas instituições para angariar atenção ao tema e não subestimar os atos de violência sofridos por elas. Todavia, tal abordagem delegou ao Conselho de Segurança o papel tradicional de protetor, aceitou as operações militares como plenamente capazes de assegurar a segurança da população e, fundamentalmente, deixou de promover a emancipação das mulheres (KIRBY; SHEPHERD, 2016).

Houve, portanto, uma perda da capacidade crítica ao não articular as mulheres como as agentes responsáveis pela mudança. A agenda foi conduzida de forma a resolver problemas, sem problematizar a realidade, reforçando, com isso, valores e estruturas. Acrescenta-se a isto a extrema valorização do Estado como promotor das ações, em paralelo a pouca ênfase conferida às lideranças femininas nas organizações civis. Em especial, a Resolução 1820 malogrou ao ser redigida a portas fechadas, sem a consulta da sociedade civil, abandonando o caráter progressista alcançado até aquele momento (SWAINE, 2009; KIRBY; SHEPHERD, 2016; REBELO, 2017).

\footnotetext{
${ }^{8}$ Estudo realizado aponta que 27\% dos acordos de paz realizados entre 2000-2015 fazem referência às mulheres, o que representa o dobro daqueles do período entre 1990-2000 (KIRBY; SHEPHERD, 2016).
} 
Desse modo, a comunidade internacional acompanha a emergência e a evolução das normas que compõem a agenda MPS, desde o ano 2000, porém, na prática, a implementação dessas diretrizes não avança no mesmo ritmo. Um bom indicativo desse quadro é a baixa porcentagem de mulheres em missões de paz e a estagnação no crescimento dessa participação, “a contribuição permanece mínima na manutenção da paz e menor no policiamento” ${ }^{9}$ (SWAINE, 2009; DONADIO; RIAL, 2015; BARROW, 2016; KIRBY; SHEPHERD, 2016, p. 374, tradução nossa).

Na tentativa de suprir esse descompasso foram propostos os Planos de Ação Nacionais (SOTO; PARDO, 2016). De acordo com a Resolução 1889, os PANs são a principal ferramenta para garantir a accountability da Resolução 1325, a partir dos quais os Estados podem demonstrar os estágios que percorreram para cumpri-la (SWAINE, 2009).

Assim, um PAN prevê a apresentação de: estratégias, áreas prioritárias, funções, indicadores e mecanismos de avaliação. Independentemente de seu formato, a orientação central é de que as políticas propostas não tenham mero efeito declaratório, mas que estabeleçam tarefas, responsabilidades e mecanismos de fiscalização. A sociedade civil e a academia são parceiros fundamentais no seu desenvolvimento e avaliação (MILLER; POURNIK; SWAINE, 2014).

A produção de PANs provoca, entretanto, uma reflexão no sentido de que os princípios propostos pela Resolução 1325 deveriam estar naturalmente presentes nas políticas, nacional e internacional, não sendo, portanto, necessária a idealização de planos específicos. Em contrapartida, a confecção de planos, em separado, diminui o risco de que as iniciativas se percam no nível da implementação (SWAINE, 2009).

Outrossim, o seu desenvolvimento é vantajoso, ao passo que promove coordenação entre as agências do governo, a execução de um plano permite ao departamento de governo uma visão clara do trabalho e a identificação de potenciais parceiros da sociedade civil em sua implementação. Colabora para o monitoramento e a avaliação, logo promove uma melhor prestação de contas. Intensifica, também, a discussão sobre o tema, ao reunir representantes de diversos setores em fóruns para compartilharem suas experiências (POPOVIC; LYYTIKAINEN; BARR, 2010).

Contudo, a produção dos PANs não ocorreu de forma imediata à adesão a Resolução 1325; o primeiro PAN foi publicado apenas em 2005, na Dinamarca. Nos anos seguintes diversos países europeus também o fizeram, assim como na África Subsaariana, região que registra um elevado número de PANs, diferente da América Latina e Ásia-Pacífico, onde poucos países possuem um plano (MILLER; POURNIK; SWAINE, 2014).

Em 2019, oitenta e três Estados-Membros da ONU (43\% do total) possuíam um PAN, e o mais recente deles teria sido produzido por Bangladesh (PEACEWOMEN, s.d.). Diante disso, e assumindo o posicionamento de que os PANs são necessários para os Estados progredirem no trato da agenda MPS, mas que não são um fim em si mesmos; ou seja, carecem de mecanismo de avaliação e responsabilização dos governos por seus compromissos (MILLER; POURNIK; SWAINE, 2014), a próxima seção identificará a estratégia empírica que será utilizada para aprofundar o estudo dos PANs de Argentina, Brasil, Chile e Paraguai - os únicos países que, até o momento, divulgaram um plano na região Sul-Americana.

\section{Estratégia empírica}

Este artigo emprega duas técnicas de análise, a primeira delas sugere uma análise sistemática dos casos, em um estudo aprofundado dos contextos, o que nos fornecerá insumos para generalizações, a partir do cruzamento de resultados (YIN, 2015). Em sequência, é proposta uma comparação estruturada, a qual consiste em analisar diferentes casos pautados em categorias comuns, ampliando o conhecimento sobre o fenômeno.

Para tanto, foi realizada uma revisão da literatura em periódicos científicos, nacionais e internacionais, por trabalhos que adotassem estratégias de análise do conteúdo dos Planos de Ação Nacionais como forma de sistematizar e

\footnotetext{
${ }^{9}$ While the number of female personnel included in UN missions overall has increased, their contribution remains minimal in peacekeeping, and minor in policing.
} 
compreender as informações presentes e ausentes em cada um deles. Essa exploração do campo resultou em três artigos que se dedicam ao estudo mais detido dos PANs, brevemente relatados a continuidade.

Na análise de Fritz, Doering e Gumru (2011) os PANs foram abordados a partir de vinte critérios divididos em seis categorias, quais sejam: aspectos gerais; preparação do plano; implementação do plano; pontos sensíveis; conteúdo; e, avaliação e monitoramento. No estudo elaborado por Miller, Pournik e Swaine (2014) foram estabelecidas quatro categorias principais: informações básicas; elaboração; implementação; e, monitoramento e avaliação. Tais categorias foram subdivididas em elementos e buscou-se verificar a menção de cada um deles. Por fim, Shepherd (2016) propôs a exploração de duas categorias primárias: orientação e competência; a partir delas verificou o enquadramento geral do plano, o uso de imagens, a relação entre segurança e desenvolvimento, a inclusão feminina nas Forças Armadas e as estratégias nacionais para a eliminação da violência contra as mulheres.

Ciente dessas três distintas abordagens e da inexistência de um regramento específico para o desenvolvimento dos planos, tampouco de expectativas mínimas para sua apresentação, este estudo opta por pautar a análise no primeiro guia elaborado para auxiliar os governos no desenvolvimento de seus PANs, realizado pela United Nations International Research and Training Institute for the Advancement of Women (UNINSTRAW) e encontra assim diversas semelhanças com os critérios estabelecidos pelas demais autoras.

O Guia elenca seis elementos como referência para o desenvolvimento do PAN

1. Razão: motivação para criação e quais são as leis que o amparam;

2. Objetivos: geral e específicos, de forma clara e realista;

3. Estratégia: percurso que será adotado para desenvolver as ações do Plano, bem como as responsabilidades de cada ator envolvido;

4. Resultados Esperados: materiais que serão desenvolvidos e eventos realizados;

5. Cronograma: prazos definidos para a conclusão da ação e para cada etapa; e

6. Orçamento: custos potenciais de todas as atividades planejadas.

Ao final, discorre, também, sobre os desafios que, em geral, os planos enfrentam na implementação, são eles:

7. Financiamento: ausência de fundos;

8. Coordenação: desarticulação entre os atores; e

9. Accountability: ausência de um sistema de prestação de contas e avaliação.

Essas noves categorias guiarão a comparação dos cinco PANs da América do Sul. Outro aspecto igualmente passível de comparação seria o tamanho do documento. Enquanto um plano breve é, geralmente, mais efetivo, uma análise mais robusta oferece a oportunidade de apresentar outros compromissos do governo sobre a equidade de gênero. Entretanto, dado a ausência de padrões prévios, alguns planos podem incluir cópias de resoluções, apêndices e imagens, o que dificultaria a comparação; por essa razão, optou-se por retirá-lo (MILLER; POURNIK; SWAINE, 2014). Desse modo, o artigo segue com a seção de análise, a qual está segmentada em dois estágios: apresentação dos casos e comparação dos resultados.

\section{Análise - parte I}

Na América do Sul foram redigidos, até 2019, cinco Planos de Ação Nacionais, por ordem de aprovação, são eles: Chile, Argentina, Chile (atualização), Paraguai e Brasil. O primeiro plano do Chile foi publicado em 2009, enquanto os três seguintes foram anunciados apenas em 2015. A letargia da região foi atribuída, por alguns, ao pouco conhecimento e a falta de informação sobre a existência e o conteúdo da Resolução 1325, tanto de líderes quanto da sociedade em geral (FRITZ, 2010). 
No Chile, entretanto, algumas condições teriam colaborado para o seu despertar prematuro, a exemplo da participação do país na Organização para Cooperação e Desenvolvimento Econômico (OCDE) e do papel de liderança exercido pela então presidenta Michelle Bachelet (MILLER; POURNIK; SWAINE, 2014). Acrescenta-se a isso o pioneirismo do país, na América Latina, no estabelecimento de uma política de igualdade de oportunidades entre homens e mulheres ${ }^{10}$ (CASTRILLON, 2013).

Com isso, o primeiro Plano de Ação Nacional chileno é lançado no mês de agosto de 2009, durante a presidência de Bachelet. A elaboração embora bastante célere, ocorreu de forma colaborativa, por meio da realização de diversas reuniões, das quais participaram ministérios, Forças Armadas, sociedade civil, organizações de direitos das mulheres, academia e, também, representantes do governo de Argentina, Bolívia, Equador e Espanha ${ }^{11}$. Sua autoria final foi atribuída ao Ministério das Relações Exteriores, Ministério da Defesa e ao Servicio Nacional de la Mujer (SERNAM) (MARCHETTI, 2017).

O plano foi amparado por acordos anteriores firmados pelo país como: a CEDAW, a Declaração e Plataforma de Ação de Pequim, o Estatuto de Roma e a Convenção de Belém do Pará (RAABER, 2014). Paralelamente, em 2005, o Chile havia iniciado um conjunto de mudanças no setor da defesa, motivadas, em grande medida, pela liderança feminina do Ministério. Assim, dentre os antecedentes institucionais estão a significante participação do país em operações de paz e a participação formal das mulheres nas Forças Armadas (MARCHETTI, 2017).

Destaca-se a importante contribuição das organizações da sociedade civil e da academia na produção do documento, responsáveis por frisar a necessidade do monitoramento civil na evolução das ações, propondo que se atuasse de forma coordenada, com enfoque nos Direitos Humanos e o estabelecimento de um Conselho de Ministros para Igualdade de Oportunidades (RAABER, 2014; SOTO; PARDO, 2016).

No tocante ao financiamento, o plano foi exclusivamente subsidiado pelo Estado e a responsabilização pelas ações recaiu sobre seus principais autores - Ministério das Relações Exteriores, Ministério da Defesa e SERNAM -, em especial ao Ministério da Defesa. Entretanto, não foram revelados o orçamento e os gastos com as ações, tampouco houve a criação de um fundo especial. Em detrimento a sociedade civil não testemunhou resultados das ações e se ausentou da elaboração do segundo PAN (RAABER, 2014).

O segundo PAN, originalmente planejado para 2013, sofreu sucessivos adiamentos sendo divulgado em 2015. Esse novo documento estabeleceu como áreas prioritárias: prevenção e participação; para isto, focou em programas de educação e treinamento e no aumento de mulheres nas missões. Elencou uma série de objetivos estratégicos e para eles uma soma de objetivos específicos, atividades a serem realizadas, indicadores, metas, responsáveis e participantes (MARCHETTI, 2017).

A título de exemplo, estabeleceu, como objetivo estratégico, o fortalecimento das competências dos(as) funcionários(as) públicos(as) em matéria de gênero, e orientou a realização de pesquisas acadêmicas. Tratou, também, da compilação de informações estatísticas sobre os casos de violência baseada no gênero, mensurando-as por meio de indicadores. Propôs, ainda, a concessão de maior autoridade ao Comitê Interministerial, formado por Ministério da Defesa, Ministério da Mulher e Equidade de Gênero e pela Chancelaria (SOTO; PARDO, 2016; MARCHETTI, 2017).

Comparativamente ao primeiro plano nota-se que as atividades e os indicadores foram mais bem detalhados, porém os objetivos permaneceram pouco ambiciosos e não foi estabelecida uma forma de monitoramento sistemático. Durante o processo de elaboração a sociedade civil, diferentemente do primeiro, teve participação marginal. Em relação

\footnotetext{
10 "Política de Integración y participación de las mujeres en las fuerzas armadas y de orden y seguridad" advinda de um apêndice do Livro Branco, de 2002. Essa política afirma a igualdade entre homens e mulheres, com regras gerais para ambos e regulação de situações de exceção; promove a integração participativa em atividades profissionais; avalia a competência profissional baseada em conhecimento, méritos e habilidades; emprega a equidade para um tratamento justo, ainda que não idêntico; e, assume a liderança na condução do processo de participação e planejamento permanente (MARCHETTI, 2017)

${ }^{11}$ Nomeadamente as organizações da sociedade civil e instituições da academia que participaram foram: Corporación Humanas, Facultad Latinoamericana de Ciencias Sociales (FLACSO), Universidad de Chile e Universidad Arcis. No que diz respeito aos ministérios, houve a contribuição dos ministérios da Saúde, Educação e Planejamento (RAABER, 2014).
} 
ao financiamento, o segundo documento afirmou que cada instituição envolvida deveria prover fundos para financiar as atividades e incentivou as demais instituições participantes a também contribuírem (RAABER, 2014).

Na Argentina o Plano de Ação Nacional foi divulgado, em 2015, pela presidenta Cristina Fernández Kirchner, após um longo processo de preparação e consultas, sob a liderança do governo central. O primeiro encontro para discussão da temática foi realizado em 2008 intitulado: Primer Taller Regional para el desarrollo de una política de género en el marco de las Operaciones de Paz y Ayuda Humanitarias. Paralelamente, foi criada a Representacion Especial para Temas de la Mujer em el Ámbito Internacional del Ministerio de Relaciones Exteriores y Culto com atribuição de articular as distintas instâncias governamentais para elaboração do plano.

Em 2011, deu-se início, de fato, a produção de um projeto preliminar, o qual contou com a contribuição do Ministério das Relações Exteriores, instituições envolvidas com a temática e representantes da sociedade civil (MARCHETTI, 2017).

O PAN argentino centrou-se na inclusão feminina na política e na introdução da perspectiva de gênero em todos os aspectos da segurança e defesa nacional (POPOVIC; LYYTIKAINEN; BARR, 2010). Dentre os objetivos estão: aumento da presença de mulheres em operações de paz, maior envolvimento nas negociações e proteção dos Direitos Humanos de mulheres e meninas. Para tanto, algumas das estratégias são: o fortalecimento do Conselho de Política de Gênero do Ministério da Defesa, a promoção de ações coordenadas entre as agências responsáveis e o estabelecimento de indicadores (SOTO; PARDO, 2016).

No Paraguai o Plano de Ação Nacional, lançado em 2015, foi resultado de uma ação conjunta que envolveu o Ministério da Relações Exteriores, o Ministério das Mulheres, o Ministério da Defesa, o Ministério do Interior e o Comando Militar.

O plano prevê a eliminação de barreiras internas que impeçam a participação feminina na negociação e resolução dos conflitos e em todos os aspectos da paz e da segurança, porém não menciona assuntos sensíveis às mulheres como a violência armada (NATIONAL, s.d). Ao mesmo tempo que é bastante preciso, ao estabelecer um cronograma com prazos de execução de cada ação (entre 2016 e 2020), falha ao não designar um orçamento específico para o setor (MARCHETTI, 2017).

O plano está organizado em metas de curto e longo prazo, no curto prazo buscam: aumentar a participação das mulheres nos processos de tomada de decisão, incorporar a perspectiva de gênero, promover a cultura da paz e a coordenação intersetorial. No longo prazo almeja contribuir para a eliminação de barreiras culturais que colocam obstáculos a plena participação das mulheres na esfera social (SOTO; PARDO, 2016).

Outrossim, destacam-se as proposições de eixos de ação, a criação de indicadores para medição, a atribuição de responsáveis para execução de cada atividade e o estabelecimento de instâncias de monitoramento e avaliação (SOTO; PARDO, 2016).

No Brasil o Plano Nacional de Ação (PNA), apresentado em março de 2017, contou com a contribuição da Comissão de Gênero do Ministério da Defesa (CGMD) em sua elaboração. A CGMD foi criada, em 2014, com a pretensão de orientar a atuação do Ministério da Defesa e de liderar a confecção do PNA. No entanto, sua composição majoritariamente masculina, por vezes dificultou as tratativas; resistentes à inclusão da questão de gênero na pauta. Acrescenta-se a isto o parco debate sobre o tema no Legislativo e na mídia (GIANNINI; LIMA; PEREIRA, 2015).

Os encontros para confecção do plano foram organizados pelo Ministério das Relações Exteriores, com a participação do Ministério da Defesa, Ministério da Justiça e Segurança Pública e Ministério dos Direitos Humanos. Grupos da sociedade civil, como o Instituto Igarapé, e organizações internacionais, como a ONU Mulheres, foram fulcrais para que 
o debate não ficasse limitado ao setor da defesa ${ }^{12}$. Outrossim, foi aberto um portal online para reunir as demandas da sociedade civil (GIANNINI; LIMA; PEREIRA, 2015; DRUMOND; REBELO, 2018).

Em encontro realizado em março de $2016^{13}$ foram definidos aspectos importantes para a produção do PNA, tais como compreensão do contexto local; definição de mecanismos efetivos de coordenação, compartilhamento de informações, avaliação e monitoramento; fixação de resultados esperados, objetivos estratégicos internos e externos e metas temporais; e, delimitação de recursos financeiros para a materialização do plano; porém, nem todos, foram levados em consideração na publicação do PNA.

O PNA brasileiro erigiu-se sob quatro pilares: (i) Participação; (ii) Prevenção e Proteção; (iii) Consolidação da Paz e Cooperação Humanitária; e, (iv) Aprofundamento, Sensibilização e Engajamento. Para Drumond e Rebelo (2018) o plano surpreende positivamente ao se comprometer a ampliar a participação de mulheres em iniciativas de promoção e consolidação da paz. Contudo, perduram desafios a serem superados, o mais importante deles: aumento da participação das mulheres nas Forças Armadas, polícia e diplomacia, eliminando barreiras de entrada, diferenças salariais e promovendo condições laborais que colaborem para o pleno exercício de suas atribuições, com atenção à família. Para além disso, a importância de uma abordagem que reconheça a pluralidade das mulheres brasileiras, integrando-as aos programas e políticas.

\section{Análise - parte II}

Em fase comparativa foram utilizadas as nove categorias expostas na seção empírica, com o intuito de identificar as principais diferenças entre os PANs de Argentina, Brasil Chile e Paraguai. A partir da leitura de cada plano, foram conferidos os valores 1 para a presença e 0 para a ausência de cada item:

\begin{tabular}{|c|c|c|c|c|c|}
\multicolumn{2}{c|}{} & Quadro 2-Comparação Planos Nacionais de Ação América do Sul \\
\hline & ARGENTINA & BRASIL & CHILE I & CHILE II & PARAGUAI \\
\hline Razão & 1 & 1 & 1 & 1 & 1 \\
\hline Objetivos & 1 & 1 & 1 & 1 & 1 \\
\hline Estratégia & 1 & 1 & 1 & 1 & 0 \\
\hline Resultados & 0 & 1 & 0 & 0 & 1 \\
\hline Cronograma & 0 & 0 & 0 & 0 & 0 \\
\hline Orçamento & 0 & 0 & 0 & 0 & 0 \\
\hline Financiamento & 0 & 0 & 1 & 1 & 1 \\
\hline Coordenação & 0 & 0 & 0 & 1 \\
\hline Accountability & 1 & 0 & & \\
\hline
\end{tabular}

Fonte: Elaborado pela autora.

A comparação dos países possibilita observar que todos apresentam em seu plano as razões para sua elaboração, citando o arcabouço de leis nacionais e internacionais que dão suporte para a produção. Nesse quesito, a Argentina merece atenção ao demonstrar grande preocupação em apresentar o marco legal, nacional e internacional, que dá sustentação à adesão da Resolução 1325 e confecção do plano, são ao todo seis páginas que tratam essa temática.

No que tange aos objetivos gerais e específicos os cinco planos são bastante explícitos em sua menção. Já as estratégias para a consecução dos citados objetivos, também, foram traçadas por todos os planos, bem como houve uma distribuição entre os órgãos competentes das funções. Com referência ao último ponto o primeiro plano de ação do Chile

\footnotetext{
${ }_{12}$ Miller, Pournik e Swaine (2014) já haviam observado a importância das organizações internacionais, sobretudo da ONU e seus braços, no desenvolvimento dos PNAs em países com menor renda.

${ }^{13}$ A oficina intitulada: "Consolidando a estratégia do Brasil sobre mulheres, paz e segurança: da agenda global ao contexto nacional”, foi realizada no Instituto Rio Branco e organizada pelo Ministério das Relações Exteriores, em colaboração com a Fundação Alexandre de Gusmão (FUNAG), ONUMulheres e o Instituto Igarapé. Entre os participantes estiveram presentes representantes de Ministérios, de organizações internacionais e da sociedade civil.
} 
destoa dos demais dado a inclusão de diversos Ministérios como responsáveis para execução das atividades - Ministério da Saúde, Ministério da Educação, Ministério do Planejamento, Ministério da Defesa e Ministério das Relações Exteriores. $\mathrm{Na}$ linha resultados esperados observamos que apenas o Brasil e o segundo plano de ação do Chile mencionaram de forma explícita o que pretendem com cada ação. No caso do Chile, o seu segundo plano demonstra uma preocupação desde o princípio com a proposição de indicadores, o que contribui para a delimitação das metas.

O seguinte elemento analisado foi o estabelecimento de um cronograma para a execução das atividades, neste aspecto apenas o Paraguai apresenta um esboço de planejamento. O país define um período anual, segmentado em cinco momentos, demarcando o início e a duração de cada atividade. O segundo plano nacional do Chile menciona, vagamente, que as atividades serão executadas entre os anos de 2015 e 2018, sem estabelecer ordem cronológica e prazos de execução para elas.

A observação das linhas orçamento e financiamento revela que nenhum dos países inseriu em seus planos esses elementos. O Chile em ambos os planos faz menção breve ao tema, no primeiro deles afirma que será atribuição intersetorial buscar por recursos necessários para as atividades, porém não apresenta valores, tampouco quais agências proverão o financiamento. No segundo plano o financiamento é incluído como um tópico, porém bastante sucinto, não correspondendo a mais de duas linhas.

A coordenação entre os atores do processo, uma preocupação para a boa condução das atividades, foi tratada por Chile e Paraguai em seus planos. O Paraguai menciona logo no início do plano o tema da coordenação interinstitucional, estabelecendo uma área estratégica dedicada ao seu aprimoramento, do mesmo modo faz o Chile, ao criar um Comitê Interministerial para promover a coordenação.

Por fim, a última linha do quadro comparativo avalia a prestação de contas e a avaliação. Neste aspecto Argentina, Chile (PAN II) e Paraguai, elencam indicadores com a pretensão de avaliar o resultado, no plano argentino foram estabelecidos os responsáveis pela elaboração de tal avaliação. No Brasil esse atributo não foi incluído.

De modo geral, o segundo plano de ação chileno e o plano de ação paraguaio são aqueles que mais se aproximaram da totalidade dos critérios avaliados por esta pesquisa, os dois países possuem seis deles. Contudo, diferenciam-se entre si, pois o Paraguai estabeleceu um cronograma para o cumprimento das atividades e o Chile fixou os resultados esperados. A Argentina e o Brasil possuem, cada um, quatro dos atributos, comparativamente a Argentina deixou de apontar os resultados esperados e propôs um sistema para a prestação de contas, já o Brasil descreveu os resultados esperados e não se ocupou com a accountability.

\section{Conclusões}

A execução deste estudo nos permitiu compreender, em linhas gerais, como se deu o processo de formulação dos Planos de Ação Nacionais internacionalmente e nos quatro países que, até o presente momento, apresentaram o documento na América do Sul. O que possibilitou realizar, em sequência, uma análise comparativa dos conteúdos expostos em cada um deles, a partir dos elementos compreendidos como fundamentais.

Pôde-se observar que os quatro países foram bastante cautelosos no processo de desenvolvimento dos planos o que fez com que, em geral, eles tardassem mais que o previsto para serem apresentados, como resultado houve uma criteriosa descrição das possíveis atividades a serem realizadas e a incumbência de diversas instituições.

Portanto, é positivo mencionar que em todos os planos analisados as tarefas foram cuidadosamente detalhadas, algo notório de ser pontudo, pois a ausência de especificação de ações e atores pode gerar, na fase de implementação, o tratamento da questão como um problema de todos e de responsabilidade de ninguém.

Conquanto, os planos falharam ao não se aterem às questões práticas como a alocação de recursos, incorrendo no risco de que mesmo definidos os atores eles não assumam a responsabilidade de custeio das tarefas, dificultando a 
implementação. Com isso, os países sul-americanos integram a infeliz maioria de países que não reserva fundos específicos para atingir os resultados de seus PANs.

Destarte, este estudo conclui com uma advertência aos especialistas sul-americanos envolvidos na confecção dos planos, ressaltando a necessidade de que em novas edições dediquem maior atenção ao estabelecimento de prazos, os quais estejam atrelados a um orçamento compatível; e estimula pesquisas futuras a compreenderem as razões para que os Estados omitam e/ou não especifiquem em seus documentos a fonte dos recursos para implementação das ações propostas.

\section{Referências}

AFSHARIPOUR, Afra. Empowering Ourselves: the role of women's NGOs in the enforcement of the women's convention, Columbia Law Review, v. 99, n. 1, p. 129-172, 1999.

BARROW, Amy. Operationalizing Security Council Resolution 1325: The role of National Action Plans. Journal of Conflict and Security Law, n. 21, pp. 245-275, 2016.

BARSTED, Leila. Convenção Interamericana para Prevenir, Punir e Erradicar a Violência Contra a Mulher - Convenção de Belém do Pará - 1994. In: FROSSARD, Heloisa (org.) Instrumentos Internacionais de Direitos das Mulheres. Brasília: Secretária Especial de Políticas para as Mulheres, 2006. p.140-146.

CASTRILLON, Liliana. Mujer y Fuerzas Armadas en el contexto sudamericano: una visión desde Chile. Estudios de Seguridad y Defensa, v. 2, 2013.

CEPAL; OIT. Coyuntura Laboral en América Latina y el Caribe: evolución y perspectivas de la participación laboral femenina en América Latina, n. 21, 2019.

COCHRANE, Kira. All the Rebel Women: the rise of the fourth wave of feminism. Guardian Books, 2013.

CONFERÊNCIAS Mundiais da Mulher. ONU Mulheres Brasil, Brasília, s.a. Disponível em: <http://www.onumulheres.org.br/planeta5050-2030/conferencias/>. Acesso em: 01 set. 2019.

CSNU, Conselho De Segurança Das Nações Unidas. Resolução 1325, 2000.

CSNU, Conselho De Segurança Das Nações Unidas. Resolução 1820, 2008.

CSNU, Conselho De Segurança Das Nações Unidas. Resolução 1888, 2009a.

CSNU, Conselho De Segurança Das Nações Unidas. Resolução 1889, 2009b.

CSNU, Conselho De Segurança Das Nações Unidas. Resolução 1960, 2010.

CSNU, Conselho De Segurança Das Nações Unidas. Resolução 2106, 2013a.

CSNU, Conselho De Segurança Das Nações Unidas. Resolução 2122, 2013 b.

CSNU, Conselho De Segurança Das Nações Unidas. Resolução 2242, 2015.

CSNU, Conselho De Segurança Das Nações Unidas. Resolução 2467, 2019.

DONADIO, Marcela; RIAL, Juan. La Agenda de Mujer, Paz y Seguridad en el año de su revisión: la Resolución 1325 en la esfera militar y policial. RESDAL, 2015.

DRUMOND, Paula; REBELO, Tamya. Retrocessos? “Mulheres, paz e segurança” no Brasil: o debate que não pode morrer. Diplomatique, Osasco-SP, maio de 2018. Disponível em: <https://diplomatique.org.br/mulheres-paz-e-seguranca-no-brasil/> . Acesso em: set de 2019.

FRASER, Nancy. Da redistribuição ao reconhecimento? Dilemas da justiça numa era "pós-socialista”. Tradução de Julio Assis Simões. Cadernos do Campo, n. 14/15, p. 231-239, 2006.

FRASER, Nancy. Fortunes Feminism from State-Managed Capitalism to Neoliberal Crisis. Verso: London, New York, 2013.

FRIEDMAN, Elisabeth. Gendering the agenda: the impact of the transnational women's rights movement at the UN Conferences of the 1990s. Women's Studies International Forum, v. 26, n. 4, p. 313-331, 2003. 
FRITZ, Jan Marie. Mulheres, Resolução do Conselho de Segurança das Nações Unidas 1325 e a necessidade de planos nacionais. Sociologias, n. 23, p. 340-353, 2010.

FRITZ, Jan; DOERING, Sharon; GUMRU, Belgin. Women, Peace, Security and the National Action Plans. Journal of Applied Social Science, 2011.

GIANNINI, Renata; LIMA, Mariana; PEREIRA, Pérola. Brazil and UN Security Council Resolution 1325: progress and Challenges of the Implementation Process. PRISM, v. 6, n. 1, p.179-197, 2016.

GRADY, Constance. The waves of feminism, and why people keep fighting over them, explained, Vox, 2018. Disponível em: <https://www.vox.com/2018/3/20/16955588/feminism-waves-explained-first-second-third-fourth>. Acesso em: 12 fev. 2020.

GYA, Giji. The Importance of Gender in ESDP. European Security Review, ISIS Europe, n. 34, 2007.

HILL, Felicity. How and when has security council resolution 1325 (2000) on women, peace and security impacted negotiations outside the Security Council. 2005. Dissertação (Mestrado em Relações Internacionais) - Uppsala University, Uppsala, 2005.

KIRBY, Paul; SHEPHERD, Laura. The futures past of the Women, Peace and Security agenda. International Affairs, v. 92, n. 2, p. 373392, 2016.

MATHIAS, Suzeley. Gênero, Defesa e Paz no Cone Sul. In: MATHIAS, Suzeley (Org.) Sob o signo de Atena: gênero na diplomacia e nas Forças Armadas. Ed. UNESP: São Paulo, 2009. p.17-50

MARCHETTI, Ximena. Planes de Acción Nacional sobre mujeres, paz y seguridade. Experiencias comparadas y proyecciones para el caso chileno. Revista de Derecho, v. 30, n. 2, p. 203-223, 2017.

MILLER, Barbara; POURNIK, Milad; SWAINE, Aisling. Women in Peace and Security through United Nations Security Resolution 1325: Literature Review, Content Analysis of National Action Plans, and Implementation. Working Paper, 9, Institute for Global and International Studies, George Washington University, 2014.

MUNRO, Ealasaid. Feminism: a fourth wave? Political Insight, 2013.

NATIONAL Action Plan: Paraguay. Peace Women - Women’s International League for Peace and Freedom, New York, s.d. Disponível em: <https://www.peacewomen.org/action-plan/national-action-plan-paraguay>. Acesso em: 01 set. 2018

PAZ e Segurança. ONU Mulheres Brasil, Brasília, Disponível em: <http://www.onumulheres.org.br/areas-tematicas/paz-eseguranca/>. Acesso em: 01 set. 2019.

POPOVIC, Nicola; LYYTIKAINEN, Minna; BARR, Corey. Planning for Action on Women and Peace and Security: National-level Implementation of Resolution 1325 (2000). UN-INSTRAW: Santo Domingo, 2010.

RAABER, Natalie. Financing for the Implementation of National Action Plans on UN Security Council Resolution 1325: critical for advancing women's human rights, peace and security. SURALAGA, Dewi; CABRERA-BALLEZA, Mavic (Eds.). Global Network of Women Peacebuilders (GNWP), 2014.

REBELO, Tamya. A Atuação das Organizações Não Governamentais no Conselho de Segurança das Nações Unidas: os casos das agendas temáticas sobre Crianças e Mulheres. 2017. Tese (Doutorado em Relações Internacionais) - Universidade de São Paulo: São Paulo, 2017.

SHEPHERD, Laura. Making war safe for women? National Action Plans and the militarization of the Women, Peace and Security agenda. International Political Science Review, v. 37, n. 3, p. 324-335, 2016.

SOTO, Daniela; PARDO, Pablo. Planes de Acción Nacional para la Resolución 1325: Casos de Argentina, Chile y Paraguay. Regional Insights, n. 3, William J. Perry Center for Hemispheric Defense Studies, 2016.

SWAINE, Aisling. Assessing the Potential of National Action Plans to Advance Implementation of United Nations Security Council Resolution 1325. Yearbook of International Humanitarian Law, v. 12, p. 403-433, 2009.

TITUNIK, Regina. The First Wave: Gender Integration and Military Culture. Armed Forces \& Society, v. 26, n. 2, p. 229-257, 2000.

TRYGGESTAD, Torunn. Trick or treat? The UN and Implementation of Security Council Resolution 1325 on Women, Peace, and Security. Global Governance, v. 15, p. 539-557, 2009.

UNDP, United Nations Development Programme. Parliaments as partners supporting. The women peace and security agenda. Oslo, 2019.

VIOTTI, Maria Luiza. Declaração e Plataforma de Ação da IV Conferência Mundial Sobre a Mulher - Pequim, 1995. In: FROSSARD, Heloisa (org.) Instrumentos Internacionais de Direitos das Mulheres. Brasília: Secretária Especial de Políticas para as Mulheres, 2006. p.148-258.

WEST, Lois A. The United Nations women's conferences and feminist politics. In: M. K. Meyer, E. Prugl (eds.) Gender politics in global governance. New York: Rowman \& Littlefield, 1999. p. 177-193 
YIN, Robert K. Estudo de Caso: planejamento e métodos. Porto Alegre: Bookman, 2015.

Funções de colaboração exercidas

Natália Diniz Schwether

Conceituação; Metodologia; Curadoria de dados; Análise formal; Investigação; Escrita (primeira redação); Escrita (revisão e edição);

Informações fornecidas pelos(as) autores(as) de acordo com a Taxonomia de Funções de Colaborador (CRediT) 